\title{
Doing narrative research? Thinking through the narrative process.
}

Tina Miller, Oxford Brookes University

\section{Introduction}

This chapter examines the growth in narrative research as a means to explore individual lives and practices of making sense. The so called 'narrative turn' can be traced through the social sciences as a response to more complex social worlds and associated epistemological challenges. In this chapter a feminist perspective is taken in order to explore the process of taking a narrative approach in the context of exploring women's lives through periods of transition. The undertaking of research which collects personal accounts or 'voices' is now commonplace in many areas of social science research, yet the theoretical framing in studies taking this approach is not always clear or present. It is timely then to consider aspects of the narrative endeavour and contemplate 'what actually constitutes narrative research'? This question will be explored through a focus on feminist, philosophical and theoretical considerations which can provide a starting point and frame for narrative research, together with examples of biographical sense-making from a qualitative longitudinal research (QLR) study on transition to first-time motherhood. The potential for rich knowledge production in relation to practices of gendered agency and narrative construction, reconstruction and the production of 'counter' narratives will be demonstrated through this study. The chapter will also provide some useful strategies for those embarking on research projects which seek to explore how individuals make sense of change and transitions in their lives. Focusing on the ways in which narratives can be traced through the accounts individuals share with us as researchers can illuminate understandings of selves and practices of gendered identity work, as participants make sense of personal experiences which are also societally defined (for 
example, becoming a mother) and taken-for-granted. This approach can reveal points of disjunction and overlap between societally-dominant, powerful discourses, normative assumptions and individual, everyday experiences. The rich and nuanced findings from such a narrative approach can contribute towards theorisations of power, gendered selves and identities.

\section{Background: feminist, philosophical and theoretical considerations}

A major feminist contribution to research has been to challenge particular ways of knowing and the assumptions which underpin traditional epistemological positions (Stanley and Wise, 1983; Ribbens and Edwards, 1998; Harding, 1987). Accepting aspects of the social world as complex and messy and that lives are experienced from unequal individual (classed, 'raced' and gendered) positions, renders positivist expectations of measurement and external validity as unhelpful. Feminist contributions to epistemological debates have led to increased scrutiny of the ways in which research is conducted and the processes involved including the researcher's role and subjectivity. When research encompasses more private and personal aspects of lives these reflections become even more salient. So too managing the ambiguity which can arise as we oscillate between 'the social construction and material production of knowledge' required in public, academic, policy spheres, while remaining 'faithful' to forms of knowledge shared in interviews (Ribbens and Edwards, 1998:2; Cooper and Rogers, 2015). The importance of reflecting on research encounters, how the researcher is placed, what is shared and what is not, all become significant aspects of developing sensitivity as a researcher, especially when the focus is on accounts of subjective experience and how these are narrated and 'heard' (Birch and Miller, 2000; Fawcett and Hearn, 2004; Mauthner, 2000; Miller, 2005). The growth of interest in narratives more generally and biographical, or self- 
narratives in particular in qualitative research mirrors other changes in late modernity. In contexts where individuals are faced with greater uncertainty, more rapid transformations and (apparently) more 'choices', practices of reflexivity ${ }^{i}$ have become an important aspect of sense making in everyday lives (Andrews et al, 2013; Holstein and Gubrium, 2000). As such a focus on narrative has been argued to better help the social scientist understand individual accounts of more complex daily living and projects of self and 'narrative methodologies have become a significant part of the repertoire' of available research tools to aid this endeavour (Andrews et al, 2013; Lieblich and Josselson, 1997; Fraser, 2004; Chamberlayne, 2000; Riessman, 1993; 2008).

Narrative methodologies have ranged from exploring individual, subjective experiences to group and organisational dynamics to document analysis, and have been engaged from a range of disciplinary perspectives (Smith and Sparkes, 2008; Wengraf, 2001; Andrews et al, 2013). Yet claims to be taking a narrative approach often appear based on widely varying understandings (or lack) of the philosophical and/or theoretical roots from which the tradition emanates and an understanding of these is important in developing an appropriate methodological approach. Whilst most qualitative research may be seen to produce narrative accounts in some form, for example transcribed texts generated from an interview encounter, such studies do not all frame themselves in terms of taking a narrative approach. Even when a narrative approach is claimed, the work may actually only be regarded as narrative in that it emanates from a verbal account given by a participant. In practise lots of different approaches to doing narrative research occur and its wide use and variable interpretation has, according to Polkinghorne, 'sometimes led to a lack of clarity and precision' (1995:5). It is important then in research projects to think about and provide a rationale for the approach taken and this should be underpinned by a philosophically informed, theoretical frame through which a case/rationale for the approach taken is made. Thus the use of narrative as a method to 
explore how individuals account for, and make sense of their actions, requires sensitive and transparent application. It also requires continual reflection as (often unforeseen) 'dilemmas' can be encountered at any point as the research unfolds (Ribbens and Edwards, 1998; Mauthner, 2000).

In my own research I have used an approach which focuses on biographical narrative construction and self-editing/ reconstruction in order to explore experiences of personal transition as women become mothers for the first time (Miller, 2005; 2007; 2015) and transition to first time fatherhood $(2010 ; 2011)$. Although I will focus on the first of these studies in this chapter, my approach in both has involved attention to time and the 'temporal ordering of events' associated with individual transition and how these are understood and can be narrated (Hydén, 1997:50; Neale, 2013). This approach, and comparisons between the two studies, has importantly revealed the gendered aspects of behaviours and narrative possibilities: what can be said, when and by whom, as well as reflection on my role as a researcher (Fawcett and Hearn, 2004). My approach has been theoretically framed in relation to understandings of 'selves, ${ }^{\text {,ii }}$ and identities and the potential for biographical disruption and ontological insecurity which can arise / be experienced as episodes of personal change are anticipated and encountered. Taking this approach I have focused broadly and analytically on what can and cannot be said - narrated - about an (embodied and performative) experience (becoming a mother) as it unfolds. Philosophically this approach is located within traditions and debates on 'selves' and 'storied human lives' in which we 'are not only the actor, but also the author' (MacIntyre, 1981:198; Goffman, 1959; Ricouer, 1984; Frank, 1995). Through the construction and reconstruction of narrative accounts, using devices such as 'emplotment' (Somers, 1994), events are pieced together as episodes and a life is given unity and ontological coherence as sense of events is made. In practice, of course, unity and coherence may give way to (usually) temporary experiences of 'bafflement' as people struggle with 
'chaos' in their lives (Frank, 1995). In relation to new parenthood it may be that mothers are more 'at risk' of this as a consequence of the gap between societal expectations transmitted through dominant maternal and pronatalist discourses, and every-day early personal experiences of new motherhood. Thus in my approach to biographical narrative research, attention is paid to how people make sense of life events and experiences, which have the potential for biographical (and practical) disruption, for example the onset of a chronic illness, divorce or pregnancy (Bury, 1982, 2001; Plummer, 1995; Riessman, 1990). But this is not to suggest that as individuals we present ourselves through anything as contrived as ready formed, constant narratives - although we may indeed be 'rehearsed storytellers' with regard to particular aspects of our lives. But it does accept that 'lives are storied and identity is narratively constructed' (Smith and Sparkes, 2008:5; Andrews et al, 2013).

Being able to produce culturally recognisable and acceptable accounts of events is then an important feature of the storied human life. The stories we tell are guided by reference to dominant cultural, social and political discourses as we make sense of our experiences and present our gendered selves in particular and strategic ways to others (for example as a 'good' and coping new mother). Yet as noted above, some life events and life transitions may challenge our ability to do so more than others and in my research, transition to first time motherhood is such an event. Interestingly, motherhood - like so many other historically, taken-for-granted, aspects of women's lives - had not been regarded as a topic worthy of research until the 1950s when Winnicott and Bowlby independently began work (in problematic and now highly critiqued ways) on notions of 'the good enough mother' and 'attachment theory'. It was only in the 1960s and early 1970s that feminist and sociological attention brought the 'private' and historically invisible aspects of the home and women's lives in the domestic, caring sphere into an academic arena (Oakley, 1974, 1979; Rich, 1977; Firestone, 1971). In the intervening years, feminists have continued to scrutinise what and 
who gets researched as well as 'the reciprocal and relational', unequal and problematic dimensions of research relationships and researcher responsibilities (Cooper and Rogers, 2015; Edwards and Holland, 2013; Fawcett and Hearn, 2004; Alldred and Gillies, 2012; Ribbens and Edwards, 1998; Miller, 1998). Feminist-informed research designs have then paid attention how stories are narrated and shaped, told and reframed and how individuals 'actively shape and account for biographical disruption' (Riessman, 1990:1196; Plummer, 1995). In my research my analytical and interpretive job has been to distinguish and disentangle the threads of (gendered) narratives which run through the participants unfolding accounts as they become mothers for the first-time (Elvin-Nowak and Thomsson, 2001).

\section{Longitudinal research on significant personal transitions}

The UK based qualitative longitudinal research (QLR) drawn upon in this article focused on the ways in which a group of women made sense of their transition to first-time motherhood. The original phase of this study commenced in 1995 and involved interviewing women across the year in which they became a mother for the first time. A much later phase of the original study in which the women are interviewed as their child reaches 18 years of age, is currently being conducted (Miller, 2015). Interestingly although recruitment to the original study turned out to be a lengthier process than anticipated, once recruited the participant's initial expectations were that becoming a mother would be a relatively unproblematic experience. In brief, the study involved following 17 women, who were becoming mothers for the first time, across a year. The women were white, partnered or married (some in ethnically mixed relationships) and employed in occupations which mostly positioned them as middle class. The research design involved interviews on three separate occasions; before the birth, in the early weeks following the birth and at a later interview when the baby was approximately 9 -10 months old. Interview schedules were designed for each of the three interviews, based on open-ended questions which invited individuals to both reflect and 
anticipate the future. The style of questions was based on 'open-ended identity questions' used in research on identity work and cancer conducted in the USA by researchers Mathieson and Stam (1997:291). The questions I developed from this work invited reflection, for example 'I wonder if you can tell me how you felt when you found out you were pregnant?'. In this way the recorded interviews collected accounts of unfolding experiences around a particular event - becoming a mother - with the interviews closely following (in time) the participants unfolding experiences. What the interviews did not do was collect clearly formed narratives per se, but rather accounts in which (sometimes multi-layered and complex) narratives and narrative threads could be distinguished and disentangled by me as the data were analysed.

\section{Approaches to data analysis: tracing narratives}

Following verbatim transcription of the recorded interviews, what became clear, and could be documented over time as subsequent interviews were accumulated and analysed, was the ways in which diverse, multi-layered narratives were presented to serve different purposes (e.g. as a 'coping' mother) at different times within and between interviews. Analysis of the data from across the three (initial) interview points involved examining which strands of particular dominant and culturally recognisable discourses were discernible in the women's narratives, for example elements of the 'good mother' discourse as well as more challenging accounts of experiences or apparent gaps, omissions and silences (Mauthner, 2000). The next step involved carrying out detailed analysis (using transcripts, synopsis of transcripts, memoing, mind maps etc..) across each participant's interview data (x 3 individual interviews), exploring where and how emphasis was given to different aspects of dominant discourses and identity work as transition unfolded. This analysis was undertaken manually (although the transcripts have more recently been uploaded onto the data management package Nvivo). 
Analysis then moved from individual accounts to compare data across all 17 participants. In the table below are some useful preliminary questions to ask of your data collected in biographical interview encounters. These questions can help you to think about how (and what type of ) narrative(s) are apparent/ threaded through the interview data, the dominant and/or counter discourses which are drawn upon and the ways in which individuals present their selves in relation to an event/transition. They also prompt the researcher to think backwards and forwards, up and down and across their data about their own presence in shaping the data, before feeling confident about the interpretations which can be made. The list of course is not exhaustive $\mathrm{iii}^{\mathrm{ii}}$. It does not lead inevitably to particular narrative types, genres or forms (see for example Bury, 2001; Chamberlayne et al, 2000; Mishler, 1995; Riessman, 1993), but deals more with engaging the messiness of narrative endeavours before the later step of identifying and labelling (possible) narrative types and available 'storylines' as well as apparent omissions (see Miller, 2005 and 2010). 
Table 1: Getting started on narrative analysis

- Is there a chronology/trajectory around which it seems appropriate to organise the events/storylines? If not what might this suggest? What other ways of organising the data seem appropriate (and why)?

- What is dominant / emphasised and what is muted/rejected/absent in the account given (in relation to the topic under discussion)?

- What language/words are used/ repeated/ emphasised?

- What strands of discourse are apparent / drawn upon/rejected as individuals narrate their experiences e.g. the language and claims around biology and/or nature in birth and childrearing?

- What 'work' do individuals do in constructing particular versions of their selves (e.g. as a competent mother)? How do these change during the interview/ over the course of interviews?

- How do accounts shift (in single interviews and over-time in longitudinal research)? What is emphasised? What is different and what remains the same?

- What appear to be the 'risks' of sharing/revelations? (e.g. talking about the 'hard things', which may have perceived sanctions e.g. feelings of depression following childbirth)

- What appears to remain unspoken? How might silences be 'read'? (e.g. the impossibility of narrating 'chaos' as it is lived through)

- 'Tenuous selves' - In narrative presentations of selves what aspects or features remain constant and what shifts?

- Rehearsed storytellers - are there repeated versions of an event? What might 'well honed' accounts of an experience / accounts of identity infer? Why might this narrative be apparently well rehearsed? (e.g. Catherine Kohler Riessman has given an example of infertile women in India becoming rehearsed storytellers )

- Editing versions of narratives in longitudinal research. What is 'edited' and revised as earlier experiences (collected in previous interviews) are revisited and reconstructed and narrated (e.g. producing accounts which challenge or contradict dominant ideals and can be labelled as 'counternarratives')? Who edits themselves? Is anything edited / revised in the course of a single interview?

- How does the passage of time (even in a single interview) shape what is voiced and shared or revised?

- How/ do (significant/ powerful?) others feature in particular narrative threads? 
In the next sections I want to illustrate the ways in which I have undertaken narrative analysis, identifying various narrative practices - narrative construction, narrative reconstruction, lapsed narratives and producing counter narratives - which I have identified as practices that the participants engaged as they presented their (shifting) selves and identities through a year of interviews. What was most striking in the Transition to Motherhood study was the contrast between the anticipatory narratives collected during the antenatal interviews and data from the final interviews (in the original phase of the study), which were conducted almost a year later at around nine months following the birth of the baby. As the women in the study attempted to make sense of their selves as new mothers, they used different strategies to construct what they perceived to be culturally acceptable accounts of new motherhood. But eventually as their skills and confidence in their own mothering abilities grew, this gave way to more authoritative and challenging ('counter') narrative accounts (Miller, 2007; Somers, 1994). For all the women, transition to motherhood was different to what they had expected and felt they had been prepared for by those they had previously regarded as experts.

Given both the moral minefield in which motherhood is lived out and the 'gendered moral rationalities' that shape social negotiations around the spheres of mothering and paid work, doing mothering is a complicated and sometimes 'risky' business (Duncan and Edwards, 1999; Miller, 2005). When asked about their feelings on becoming mothers in the second (early postnatal) interview, many of the participants spoke of coping with the practical aspects of mothering. But there was ambivalence about actually feeling like mothers in those early weeks. Many were still coming to terms with the, for most, unanticipated scale of what becoming a mother entailed both physically and emotionally. Yet during the interviews women could be seen to juggle their contradictory feelings. They worked hard to make sense 
of the confusion they were experiencing and to confirm that by the time of the interview they were 'coping'. However they intimated that this was a new phase and that previously they had not felt they were coping - 'but if you'd come last week'. In the following extract, we can see the ways in which Helen ${ }^{\text {iv }}$ uses various devices, temporal and linguistic to produce what she feels is an acceptable and coherent account of her early mothering experiences. Helen begins by reflecting on the antenatal preparation,

"The only thing that I ... I could possibly sort of criticise on now ... I wouldn't say it as a criticism, but I was not prepared for at all [was] the emotional changes of when you come home and suddenly you're living this story life when you have the baby and suddenly when you come home and after all the visitors have started to dwindle off and it's just you that's left, as to how your life is possibly, you know, going to change, that there is going to be no normality whatsoever ... I suppose I've been, you know, quite a controlled ... well, I was in control of my own life, I knew what I was doing and every day I was quite organised and things, and that's completely gone out of the window. And I would say that I hadn't really been prepared for those feelings of actually being out of control, which I would say probably only the last week that I've actually got on top of it and I'm actually starting to feel a little bit more in control" (Helen, early postnatal interview).

Helen tentatively voices some concern, 'I wouldn't say it as a criticism' of her antenatal preparation. But crucially her voicing of earlier difficulties is within the context of 'only the last week ... actually starting to feel a little bit more in control'. To admit to, or to actually experience feeling out of control ('chaos'), may mean that it is impossible to construct a coherent, or publicly recognisable, narrative. To admit to others, particularly professionals - 
or even researchers (like me) who are also mothers - that you are experiencing difficulties, has all sorts of implications for how you might feel you will be perceived. As a feminist researcher I found myself wanting to reassure the women that others had shared their 'difficult' experiences too.

By the time of the final interviews an interlude of nine months has elapsed since the birth of their children, and experiences remained varied. Interestingly, some women who had previously spoken of their immediate, 'natural' identification with being a mother, now contradicted their earlier versions of their experiences. For example, in the following short extracts Faye's words from the two interviews are juxtaposed:

"Yes, it comes really naturally to me, which I wasn't sure whether it would or not" (early postnatal interview).

“I don't know, how does... how does a mother feel?... No, I don't really consider myself as...I suppose when she starts calling me Mum or something like that" (final postnatal interview).

The precarious properties of narrating a self as-new-mother are demonstrated in these extracts. As individuals we reflect, reconstruct and produce accounts within the context of other influences and in the first postnatal interview Faye confirms her 'natural' fit with mothering, as well as now revealing that she had felt uncertain that this would be the case. In so doing she confirms a recognisable aspect of the powerful 'good mother'/ 'maternal' discourse. However, the temporal ordering of events is interesting too in any analysis of narrative construction and so in Faye's extracts we also see how the elapse of time enables 
her to reflect and challenge assumptions around natural abilities (and essentialist discourses) to mother. Having survived with her baby to nine months, she is now able to risk questioning essentialist assumptions (and her own) about how 'a mother' should feel as she reveals and shares her own experiences.

As noted earlier, time and how events can be ordered are important facets of narrative research (Neale, 2013). This can be the case in single interview research design too, where attention should be similarly paid to the temporal ordering of experiences. In longitudinal qualitative research temporal ordering becomes a major focus as lives can be explored in ways which mirror unfolding events (Shirani and Henwood, 2011). In the following extracts from late postnatal interviews with Diane, Gillian and Kathryn we see how the participants experience their changing sense of selves and identity as women and mothers, and the influence of dominant discourses (of good/intensive mothering) on how they construct/reconstruct accounts of their experiences. The extracts are lengthy in order to show the 'work' participants engaged in as mentally shuffled and ordered experiences. The elapse of time enables the women to now talk in more challenging/open ways about how they feel. The narratives produced both challenge and confirm societal assumptions and dominant discourses which frame normative ideas and ideals of mothering and motherhood,

“Sometimes I do (feel like a mother) but I...I don't know. I mean I do because ... in the sense that I know that [baby] is definitely my priority, but other times I keep thinking am I really a mother? And I've felt like that from the beginning, is it really ... is it really me? You know, you just sort of don't really think you're grown up enough to be it, but as time goes on you realise you are because you have to cope with so much more every 
day, there's always something else, and you become more sort of mature, I suppose. So yes, I do feel like a mother, very mumsy" (Diana. Late postnatal interview)

"But yes, I feel much more like a mother now than I did ...I suppose I do feel like a mother... you're a person with a baby, you become a mother and you feel like a mother. And you call yourself Mummy, I suppose, don’t you, as you're going about, you know you say, 'that's Mummy', and 'don't drop Mummy’s bag again', then you call yourself Mummy so I suppose that makes you ...But like now, I could almost forget that she's there and I do feel like me. But then when she's around I suppose I'm on duty again and you feel like a mother. No, I couldn't forget that I have her, but I could imagine life ...I could imagine life without her, I could imagine going outside for a walk and forgetting her. Not that I would of course! Yes, but you know, that would be a possibility" (Gillian. Late postnatal interview)

"I worry about it the whole time. You know, I worry whether I'm a good mother, whether... whether I've got the right responses, whether I'm bonding enough with him ... That's what ...this is the bit ...that comes back to the bonding thing. No, I...I don't know. No, I don't ... my self-image hasn't changed. I don't feel ...I don't know whether I do feel like a mother? No. And that's...that's what worries me is that...I still think ...I still feel that I borrowed Rupert. It is...I still feel that he's not mine. That it's like babysitting, that I can ...I'm going to be able to give him back, that he isn't mine, and this is the whole bonding thing, and it really worries me" (Kathryn. Late postnatal interview)

Clearly, everyday life is much more complex, multi-dimensional and contradictory than we ordinarily suppose it to be and not surprisingly the narratives produced as women make sense of their experiences of transition to motherhood (which as noted earlier had been anticipated 
as unproblematic) are also fluid and simultaneously contradictory. Whilst Diana (above) talks of her doubts: 'is it really me?' she also confirms in the same extract that 'yes, I do feel like a mother, very mumsy'. Gillian talks of her different identities and the possibility that she could forget her baby but quickly asserts 'not that I would of course': clearly for 'good' mothers such an act would be assumed to be (almost) unthinkable. In Kathryn's extract, a revealing and deeply personal thread of narrative is discernible when she voices her worries around 'bonding enough' and 'right responses', she asserts that her 'self-image hasn't changed'. But sharing the feeling that you have 'borrowed' your baby is a difficult disclosure as it does not conform to culturally acceptable ways of describing experiences of ('good') mothering ${ }^{\mathrm{v}}$. What can, and cannot, be voiced around experiences of mothering, then, is clearly shaped by wider influences, and inextricably linked to socio-cultural, gendered, 'raced' and structural positions. The experiences of the women in this study were largely narrated in relation to Western culturally dominant, socially acceptable, moral constructions of 'good mothering'. However, the passage of time, and the temporal ordering of experiences, is important in relation to what can be voiced about mothering experiences and our children and when (see later extracts from Kathryn, page X). But self-surveillance may mean that some things are never voiced because they are felt to be too risky, too challenging of dominant maternal and pronatalist ideals. An interesting exchange took place in a final postnatal interview with Abigail, which touches on the parameters of what can and cannot be said in relation to our children.

ABIGAIL: I guess we're just lucky, he's a nice child. But then have you met anybody who's not liked their child?

TINA: I know people that ...there have certainly been a couple who've found it quite difficult to really fully feel even at nine months that the baby is properly theirs and ... 
ABIGAIL: But no body surely criticises their child?

TINA: No, no, no one does, no, that is true.

ABIGAIL: Because I think he's lovely, but I'm bound to.

TINA: No, that is right, no one criticises. They might feel concern that they're not doing a good job necessarily or that things could be better or whatever, but no, the babies have all been ...

ABIGAIL: Wonderful babies.

TINA: Well no, some have been little sods, I think, but ...

ABIGAIL: But do parents admit that?

TINA: But no, and some have felt that ... no, I mean, no, generally the babies have come out pretty well.

ABIGAIL: Yes, exactly. (emphasis added)

The extracts above together help to illuminate the (identity) work that participants may engage in as biographical narrative research unfolds. They also show some of the ways in which the rudimentary questions presented in Table 1 (above) can be used to begin to get a sense of - and analyse - the data collected. In this way accounts can be read as collections of different strands of narratives, in which individuals conform to, challenge or resist dominant (and counter) discourses. But equally that some things may remain unvoiced (feel off limits, or too 'risky' in some way, or at a particular time) as the exchange with Abigail (above) indicates. But things that may be unspoken in one interview may be voiced in another. In his important work on illness narratives, Arthur Frank points to the difficulty/impossibility of 
producing a coherent narrative in the midst of 'chaos' in a life and that the passage of time is needed to bring about some reflexive grasp (Frank, 1995:98). Distance from an event also provides a sense of safety: the risk of revelation may not be perceived to be so great and events may be differently ordered and understood. In the Motherhood study one participant Linda - opted out of the early postnatal interview ${ }^{\mathrm{vi}}$ and re-joined the study for the final interview. For Linda, the early postnatal period was an unexpectedly difficult - 'chaotic' period. Having been diagnosed as 'postnatally depressed' by her health visitor, a label she told me in a 'phone call that she rejected, she opted out of the early postnatal interview on the advice of her husband and health visitor. She resisted, or felt unable - or elements of both to give an account of her early mothering experiences. Linda had found out she was pregnant shortly after she had been made redundant from her office job and in the antenatal interview she had described her pregnancy as planned. In the following extract, taken from that first (antenatal) interview, Linda describes her experiences of her pregnancy, drawing on different strands of discourse to do so:

“The first three months...I didn't enjoy at all. I mean I don't think the whole pregnancy throughout has been very enjoyable, but the first three months - I wasn't sick or anything like that, it was just like ...I think it was because I was made redundant, and then I found out I was pregnant, that I think all those kind of things got on top of me, so I was not happy about the whole situation, even though I wanted to be pregnant...I think it's the fact that something else has taken over your body, the fact that you have to...change your whole way of life, really, to carry a child....You give up smoking, you give up drinking, you give up the yoghurts, the ... all the things that they tell you to give up ... and I'm thinking this is not fair. But now ...you're feeling the baby and you get to sort of understand it a bit more...I'm looking forward to having the baby" 
And later: "[It's] the thing about something else actually taking over your body ... out of control. Because I suppose I got pregnant quite late in my life ...I'm twenty nine now... Because I've had that independence, that way of life, that I could just please myself as and when, then you become pregnant, your whole body's taken over, you feel very sensitive to things that you could just sit down and cry sometimes, and the fact of becoming so large and ... not obscene but I never knew that ...I suppose I shouldn't say this, but I never knew that your backside could actually increase double the size just through being pregnant. That's happened to mine ... .Yes, I'm really ... .I know that there's going to be a bundle of joy at the end of the day ... and that's what I'm looking for, but I wouldn't go straight into being pregnant again. I think I'll have to be convinced that you know ...I feel that from being the person in charge, work-wise, to the person that is being taken over by something else or someone else, is quite a lot to take in" (emphasis added).

Linda concludes by anticipating the support she will have from her husband:

“... and I think Tom and I will actually work things out together and just get on with it ... Well, you make it together, so ...”

These extracts richly illuminate the losing of a recognisable self, a changing body, a feeling of control ebbing away in a life where individual freedoms have been earlier taken for granted/ experienced and the narrative analysis around these experiences could be unpacked further. But here what I want to show is that even in this much more candid account of the antenatal period than that provided by other participants, Linda still cleaves to snatches of more recognisably pronatalist/maternal language, for example 'a bundle of joy' and anticipates that she and her husband will 'work things out together', having made the baby 'together'. But when Linda returns to the study (having opted out of the early postnatal 
interview) for the final interview when her young son is 9 months old, she talks stridently about her experiences, 'I have been to hell and back', 'I feel cheated of the months [the baby] has been growing up' and 'I never knew bringing a baby into the world could upset your life'. In this later interview Linda makes no attempt to edit her experiences in the ways she had in the antenatal interview, through interweaving recognisably 'maternal' language. Despite significant difficulties (including the break-up of her marriage), Linda and her baby, with the help of her parents, have survived to nine months and she says she is coping: 'I can cope, I mean I'm coping with it.' Having disclosed at length in the interview her own difficult experiences Linda feels able to challenge what other people might be concealing and suggests alternative story lines ('you've not failed if something has gone wrong'):

\footnotetext{
"And when you see other people, you see them for face value, but when they go home is it a different story and do they actually tell you? And no, I don't think they do and that annoys me because I think to myself, I know what I've been through, or we as a family have been through, and I'd love other people not to know that it's us but to know that it's not all hunky dory and you've not failed if something has gone wrong ... “(emphasis added).
}

Processes of re-editing and reconstructing accounts and the production of challenging 'counter' narratives are also evident in another participant's final interview. In this interview when her baby son is 9 months old, Sarah revises aspects of her earlier version of new mothering, which she had described in her second (early postnatal) interview as 'brilliant' and her birth as 'natural' and 'what women's bodies are designed for'. In this final interview Sarah reflects on the previous months and now talks of having experienced a period of what she describes as prolonged 'shock' since the birth of her baby: 
"I actually feel that I was ... maybe not postnatally depressed, maybe in shock, definitely....I've only started smelling things again since having him, it's really weird. But I don't think it was depression, I actually think it was shock...the whole sort of... not that they tell you, it's just...the reality of it all smacks you in the face, doesn't it? You either go one way in that you just hand responsibility over to other people and you then lose your child...or you take it all in your stride and do it the right way.... which you are capable of doing. [Later] I'm not in a position (where I can) hand him to someone and say take him, and me run away.... so I just feel it's the shock of giving birth. Oh my God, it's the closest I've ever been to death, Jesus!” (Sarah, late postnatal interview, emphasis added).

Again using some of the questions in Table 1 as a starting point there is further analysis which could be undertaken on this extract. But it is included here for the purposes of demonstrating how the passage of time facilitates a reflexive grasp on events ('the reality of it all smacks you in the face'), such that experiences may be reordered and narrated in different ways. Here, challenging 'counter' narratives allude to a professional, 'expert' conspiracy of silence around birth/early mothering 'not that they tell you' alongside strands of normative discourse, for example in relation to doing things 'the right way'. Importantly data such as this has been used in my subsequent publications and presentations to a wide range of audiences (see below) and used to challenge assumptions and practices around childbirth and early motherhood support. 
The ways in which the passage of time can facilitate and prompt a reflexive narrative grasp has more recently been demonstrated through my current research which involves tracing (some of) the original sample from the Transition to Motherhood study and conducting a single interview followed by collecting optional diary reflections (Miller, 2015). A period of 17 years has elapsed since the original phase of this study and the children born then have reached 18 years of age. In the following extracts taken from a recent interview with Kathryn, she looks back across her mothering experiences and her reflections are frankly narrated,

"And I mean to be completely honest I could not have been the sort of mother who sat on the edge of a sandpit, I just couldn't do it....it was, well, often a relief to go back to work after Christmas and on Monday mornings because of the intensity and the demands that are made as a mother and I just, I know I couldn't have been a full time mother. I just wouldn't have had the patience... I just found sitting watching them on climbing frames mind numbingly boring"

“Because I think I'm stronger in myself now. Yeah I'm happier within myself now than I was then. I was very much feeling my way as a mother you know things weren't great with [husband], it was very up and down, my identity, you know I just didn't know who I was a lot of the time. Now I mean I'm happy with who I am"

"I think the most difficult thing about being a mother when they were little was having to put someone else first and not being able to do what you wanted to do because they came first.....the hardest thing was that they were so dependent and I had no freedom that was really hard" (Kathryn, Teenage child interview). 
The elapse of time and growth of her first-born baby to a young adult enables Kathryn to now give an account of her mothering which is less self-surveilled than any of the earlier accounts collected in the original study. There is also an implication that she can now give me a more 'honest' account ('I mean to be completely honest'). Now particular normative ways of being a mother and doing mothering can be openly rejected, using language not usually associated with descriptions of motherhood (even though potentially personally recognisable) as 'mind numbingly boring' and where paid work is positioned as preferable to staying at home to do mothering ('I couldn't have been a full time mother'). But there are also recognisable threads running through this much later account which connect narrations from Kathryn's earlier new mother interviews, especially her ambivalence in how she feels as a mother. In an earlier interview Kathryn was worried about how she felt as a mother 'I don't feel ...I don't know whether I do feel like a mother?' and in this much later interview the theme recurs ('I was very much feeling my way as a mother...'), but there is a resolution (perhaps because she has raised her baby who is now 18 together with a subsequent child) and she talks in terms of being 'stronger in myself now. Yeah I'm happier within myself now than I was then'. The passage of time and Kathryn's reflexive grasp also enable her to challenge normative constructions of the good - selfless - mothering discourse as she reflects on the difficulty of 'having to put someone else first'. Looking back in this more recent phase of the study it is clear that the women interviewed (to date) feel freer to now openly challenge norms and stereotypes of the 'good' mother discourses which powerfully circumscribed their earlier experiences.

\section{Opportunities and challenges: Taking a narrative approach.}

What then are the opportunities and challenges for research which is conducted on women's lives using a narrative and feminist approach? The findings from the original phase of the 
Motherhood study enabled the complex and nuanced ways in which individuals variously make sense of first-time motherhood - and how these can change over time - to be made clearer. The longitudinal interviews (and more recent data collected in the new phase of the study) have revealed how powerfully dominant (maternal and pronatalist) discourses structured the ways in which the women thought they should be experiencing and so talking about new motherhood. The possible storylines which exist in relation to western ideals of motherhood remain narrowly defined - and much more narrowly defined than the ways in which ideals of new fatherhood are constructed. Comparisons with the subsequent study on men's experiences of transition to first-time fatherhood also enabled the gendered dimensions of narrative construction processes in relation to first-time parenthood to be clearly demonstrated (Miller, 2010; 2011). The detail of the narrative analysis in the Motherhood study and the subsequent findings have provided opportunities to make public 'the material production of knowledge' to a broad range of audiences including service providers, policy makers, academics, mothers and others (Ribbens and Edwards, 1998:2). In some small way I am aware that the findings of the research have contributed beneficially to (some) women's lives, for example through changes in health visitor practise and the airing on national radio of less voiced aspects of new motherhood, for example experiences of maternal ambivalence. During the collection of data I reflected on how I (as a mother of 3 children) was placed, both as coping and 'expert' and how this contributed to the interview encounters. But I also tried to reassure the women - rejecting any positivist notion of the researcher as an unbiased, objective data gatherer - through reassuring words. However not all my participants felt I had shared or reassured enough (see for example Miller, 2005 chapter 7).

But some stories will continue to be harder to tell or remain untold such is the morally fraught, political context in which women experience motherhood. This is not only because 
the hardest experiences can be difficult to voice and share - or hear, but also because of the risk that some voices will be further silenced through the increasing ethics regulation of research practise (Miller, 2012). There are challenges for researchers to create opportunities so that voices positioned as marginal, or silenced through circumstance, are heard (for example the undocumented mother) adding vital contributions to more inclusive understandings of the range of contemporary motherhood experiences. Clearly then feminist concerns with gendered inequalities can be theorised and mapped in careful and accessible ways through the collection of rich accounts of aspects of women's lives, which too often continue to be essentialised and taken-for-granted and/or invisible in public and political contexts: caring work continuing to be a key example.

The contribution of feminist debate to research methods and more qualitative ways of examining the social world has led to a growth in 'participatory, emancipatory and egalitarian research that includes reference to the researcher's role, position and emotions' (Hansen, 2006: 65). The research outlined in this chapter has adopted a sensitive approach in which the researchers own biographical details have been shared (if requested by participants) and interview recordings (following transcription) returned to those participants who wanted them. A summary of findings was also circulated. The approach taken has illuminated how lives are situated and lived out in complex, historically and politically etched, culturally shaped and gendered structures and discourses, through which practices of agency are narrated: we understand and present ourselves through and in relation to these $\mathrm{e}^{\mathrm{vii}}$.

\section{Conclusions:}

The particular biographical narrative research approach discussed in this chapter has sought to emphasise the importance of making explicit links between theory and theoretical framing 
and sensitive, feminist research practice. At the outset the question was posed of "what constitutes narrative research' and whilst acknowledging the growth and breadth of this approach, the generic, umbrella term requires further definition by the researcher. How will you use the approach with what aim in mind? In this chapter the case was made for using a biographical narrative approach to explore periods of potential biographical disruption in women's lives as they become mothers. This approach helped to illuminate the gendered narrative practices which might be engaged as a means to present as a coping new mother. But underlying these performances, the shifting and sometimes difficult (and sometimes silencing) realities of transition and juggling of associated societal expectations and personal experiences, enabled different stories of transition to motherhood to emerge over time and be shared. Just as lives may be revealed to be messier and more chaotic, contradictory and interesting than we might at first suppose, the research process should be approached in a similar vein and a rush avoided to arrive at neat, coherent findings. But doing narrative research presents exciting, temporally-rich opportunities for researchers to examine and theorise less visible and taken-for-granted aspects of people's lives and social worlds. 


\section{References}

Alldred, P., and Gillies, V. (2012). Eliciting research accounts: Reproducing modern subjects? In T. Miller, M. Birch, M. Mauthner and J. Jessop (Eds.), Ethics in qualitative research (pp.146-166). London: Sage.

Andrews, M., Squire, C. and Tamboukou, M. (Eds) (2013) Doing narrative research. Second Edition London: Sage Publications.

Birch, M. and Miller, T. (2000). Inviting intimacy: The interview as a therapeutic opportunity. International Journal of Social Research Methodology, 3(3) pp. 189-202.

Bury, M. (1982). Chronic illness as biographical disruption. Sociology of Health and Illness 4(2):167-82.

Bury, M. (2001). Illness narratives: fact or fiction? Sociology of Health and Illness, 23: 263285.

Chamberlayne, P., Bornat, J. and Wengraf, T. (eds) (2000) The Turn to Biographical Methods in Social Science. London: Routledge.

Cooper, L. and Rogers, C. (2015), 'Mothering and 'insider' dilemmas: feminist sociologists in the research process' Sociological research online, 20 (2) 5., 10.5153/sro.3584

Edwards, R. and Holland, J. (2013). What is qualitative interviewing?, London, GB, Bloomsbury Academic.

Elvin-Nowak, Y. and Thomsson, H. (2001). Motherhood as idea and practice: A discursive understanding of employed mothers in Sweden. Gender \& Society, 15:407-28. 
Fawcett, B. and Hearn, J. (2004) Researching others: epistemology, experience, standpoints and participation, International Journal of Social Research Methodology, 7 (3), pp 201-218.

Firestone, S. (1971). The dialectic of sex. London: Jonathan Cape.

Frank, A. (1995). The Wounded Storyteller: Body, Illness, and Ethics. Chicago: Univ. of Chicago Press.

Fraser, H. (2004) Doing Narrative Research. Analysing Personal Stories Line by Line. Qualitative Social Work, 3 (2): pp. 179-201.

Goffman, E. (1959) The Presentation of Self in Everyday Life. NY: Penguin.

Hansen, E.C. (2006) Successful qualitative health research. New York: Open University Press.

Harding, S. (1987) Is there a feminist method? In S. Harding (ed.) Feminism and Methodology: Social Science Issues. Bloomington: Indiana University Press.

Holstein, J.A and Gubrium, J.F. (2000) The Self We Live By: Narrative Identity in a Postmodern World. Wiley.

Hydén, L.C. (1997) Illness and narrative. Sociology of Health and Illness. 19 (1), pp 48-69.

Lieblich, A. and Josselson, R. (1997) The Narrative Study of Lives. London: Sage.

Macintyre, A. (1981). After Virtue: A Study in Moral Theory. University of Notre Dame Press.

Mathieson, C.M. and Stam, H.J (2008) Reneotiating identity: cancer narratives. Sociology of Health and Illness 17 (3): pp. 283-306. 
Mauthner, M. (2000) Snippets and silences: Ethics and reflexivity in narratives of sistering, International Journal of Social Research Methodology, 3 (4), pp 287-306.

Miller, T. (2015) 'Going back: 'Stalking', talking and researcher responsibilities in qualitative longitudinal research'. International Journal of Social Research Methodology, 18 (3): pp 293-305.

Miller, T. (2012) 'Reconfiguring research relationships: Regulation, new technologies and doing ethical research' in T. Miller, M. Birch, M. Mauthner. and J. Jessop (Eds) Ethics in Qualitative Research. Second Edition. London: Sage.

Miller, T. (2011) Falling back into gender?: Men's narratives and practices around first-time fatherhood. Sociology, 45 (6): 1094-1109.

Miller, T. (2010). Making Sense of Fatherhood: Gender, Caring and Work' Cambridge:

Cambridge University Press.

Miller, T. (2007). 'Is this what motherhood is all about'? Weaving experiences and discourse through transition to first-time motherhood. Gender \& Society. 21: pp 337-358.

Miller, T. (2005). Making Sense of Motherhood: A Narrative Approach. Cambridge: Cambridge University Press.

Miller, T. (1998) Shifting Layers of Professional, Lay and Personal Narratives in J. Ribbens and Edwards, R. (1998) Feminist dilemmas in qualitative research. London: Sage.

Mishler, E.G. (1995). Models of narrative analysis: A typology. Journal of Narrative and Life History 5(2):87-123. 
Neale, B. (2013). Adding time into the mix: Stakeholder ethics in qualitative longitudinal research. Methodological Innovations Online, 8, 6-20.

Oakley, A. (1974). Housewife. London: Allen Lane.

Oakley, A. (1979). Becoming a mother. Oxford, UK: Martin Robertson.

Plummer, K. (1995). Telling Sexual Stories: Power, Change and Social Worlds. London: Routledge.

Polkinghorne, D. E. (1995) Narrative configuration in qualitative analysis, International Journal of Qualitative Studies in Education. 8(1), pp: 5-23.

Ribbens, J and Edwards, R. (1998) Feminist dilemmas in qualitative research. London: Sage.

Rich, A. (1977). Of woman born. London: Virago.

Ricoeur, P. (1984) Time and Narrative. Chicago: University of Chicago Press.

Riessman, C.K. (1990). Divorce Talk: Women and Men Make Sense of Personal

Relationships. New Brunswick NJ: Rutgers University Press.

Riessman, C.K. (1993). Narrative Analysis. Qualitative Research. Sage Publications.

Riessman, C.K. (2008). Narrative Methods for the Human Sciences. California: Sage Publications.

Shirani, F. and Henwood, K. (2011). Taking one day at a time: Temporal experiences in the context of unexpected life course transitions. Time and Society, 20, 49-68. 
Smith, B.M. and Sparkes, A.C. (2008) Contrasting perspectives on narrating selves and identities: an invitation to dialogue, Qualitative Research, 8(1), pp.5-35.

Somers, M R. (1994). The narrative constitution of identity: A relational and network approach. Theory and Society 23(5): 605-649.

Stanley, L. and Wise, S. (1983) Breaking Out. London: Routledge.

Wengraf, T. (2001). Qualitative research interviewing, London: Sage.

\footnotetext{
'Although 'reflexivity' may be heightened, it is not unproblematic and should be critically engaged with as a concept and practise. For example taking account of the circumstances and gendered, classed and 'raced' possibilities/choices in which practices of reflexivity are understood and engaged.

${ }^{\text {ii }}$ See Miller, T. (2005) Chapter 1 'The Storied Human Life' for more details of theoretical framing in relation to debates on selves and identity.

iii See for example Fraser, H. (2004) Doing Narrative Research. Analysing Personal Stories Line by Line. Qualitative Social Work. 3 (2): pp. 179-201.

${ }^{\text {iv }}$ All names used in the research are pseudonyms.

' Interestingly others spoke of a sense of 'borrowing' their baby in both the Motherhood and Fatherhood studies.

${ }^{\text {vi }}$ Although several telephone conversations were conducted throughout this period.

${ }^{\text {vii }}$ It is worthy of note that in the companion Fatherhood Study the men did not engage in narrative reconstruction/ editing of their accounts to the same extent as the women in the Motherhood study (see Miller, 2010 chapter 6). I have theorised this in
} 
relation to the possible (acceptable) 'storylines' available to mothers, which are more limited than those available to men who are fathers. 